\title{
KESERAGAMAN DAN PANCARAN IRIGASI PIPA PERFORASI PADA BERBAGAI KEMIRINGAN PIPA TRANSMISI
}

\author{
I Dewa Gede Jaya Negara' ${ }^{1)}$, Humairo Saidah' ${ }^{1)}$, I Wayan Yasa'), \\ dan Adhitya Halim P. ${ }^{1)}$ \\ 1) Jurusan Teknik Sipil, Fakultas Teknik, Universitas Mataram, Nusa Tenggara Barat \\ jayanegara69@gmail.com
}

\begin{abstract}
The potential of hilly dry land needs to be developed for limited land farming to have an equal distribution of food security in various potential areas. Many existing drylands, especially in hilly and sloping areas, have not been managed optimally for agriculture due to limited support for practical irrigation techniques. Utilizing differences in existing land elevation is a potential that can be exploited by irrigation techniques that require water pressure. The perforated pipe system irrigation technique has similarities to the mini sprinkler system because it uses water pressure, and it is very possible to be applied to sloped land conditions, but the ability of the perforation system needs to be known further so that it can be used for practical irrigation. For this reason, it is necessary to test the perforated irrigation system with certain variations of the slope of the beam range and uniformity, so that later it can be used as an initial reference. The test model uses a water source from a tendon as high as $3.7 \mathrm{~m}$ and with a tank capacity of \pm 200 liters. The diameter of the transmission pipe is $1 / 2$ inch with a length of 2.55 meters, and the lateral pipe as a perforation pipe with a $3 \mathrm{~mm}$ hole consists of 3 pipes with a pipe length of 4 meters with a diameter of $1 / 2$ inch and the distance between the holes of the perforation pipe is $60 \mathrm{~cm}$. The test was carried out on 4 variations of the slope of $10^{\circ}, 20^{\circ}, 30^{\circ}$, and $40^{\circ}$ with 4 variations of head 1 $=2.855 \mathrm{~m}$, head $2=2.35 \mathrm{~m}$, head $3=1.85 \mathrm{~m}$, and head $4=1.30 \mathrm{~m}$. Based on the research results, it shows that the greater the slope of the transmission pipe, the higher the head will be. The uniformity of the perforation irrigation was getting smaller the larger the slope with a minimum value of $85 \%$ and the highest being $91 \%$. A large perforation beam is obtained at transmission slopes of $20^{\circ}$ and $30^{\circ}$, namely $2.66 \mathrm{~m}$ and $2.40 \mathrm{~m}$.
\end{abstract}

Keywords: luster, perforation, a tilt of transmission 


\begin{abstract}
ABSTRAK
Potensi lahan kering yang berbukit perlu dikembangkan untuk usahatani lahan terbatas guna terjadi pemerataan ketahanan pangan diberbagai wilayah yang potensial. Banyak lahan kering yang ada terutama pada daerah yang berbukit dan berlereng belum dikelola optimal untuk pertanian karena terbatasnya dukung teknik irigasi yang praktis. Pemanfaatkan perbedaan elevasi lahan yang ada merupakan potensi yang dapat dimanfaatkan oleh Teknik irigasi yang membutuhkan tekanan air. Teknik irigasi sistem pipa perforasi memiliki kesamaan dengan sistem sprinkler mini karena menggunakan tekanan air, dan sangat mungkin dapat diterapkan pada kondisi lahan berlereng, akan tetapi kemampuan sistem perforasi yang perlu diketahui lebih lanjut agar dapat dimanfaatkan untuk irigasi yang praktis. Untuk itu perlu dilakukan uji sistem irigasi perforasi dengan variasi kemiringan tertentu terhadap besarnya jangkauan pancaran dan keseragamannya, agar nanti dapat digunakan sebagai acauan awal.Model uji menggunakan sumber air dari tendon setinggi 3.7 m dan dengan tangki kapasitas \pm 200 liter. Diameter pipa transmisi 1/2 inch dengan panjang 2.55 meter, dan pipa lateral sebagai pipa perporasi dengan lubang $3 \mathrm{~mm}$ terdiri dari 3 pipa dengan panjang pipa 4 meter diameter $1 / 2$ inch dan jarak antar lubang pipa perporasi $0,60 \mathrm{~m}$. Uji dilakukan terhadap 4 variasi kemiringan $10^{\circ}, 20^{\circ}, 30^{\circ}$ dan $40^{\circ}$ dengan 4 variasi head $1=2.855 \mathrm{~m}$, head $2=2.35 \mathrm{~m}$, head $3=1.85 \mathrm{~m}$ dan head $4=$ $1.30 \mathrm{~m}$. Berdasarkan hasil penelitian menunjukkan bahwa, semakin besar kemiringan pipa transmisi maka head yang dihasilkan semakin tinggi. Keseragaman irigasi perforasi terjadi semakin kecil jika kemiringan semakin besar dengan nilai minimum 85\% dan tertinggi $91 \%$. Pancaran perforasi yang besar diperoleh pada kemiringan transmisi $20^{\circ}$ dan $30^{\circ}$ yaitu 2.66 $m$ dan $2.40 \mathrm{~m}$.
\end{abstract}

Kata kunci: pancaran, perforasi, kemiringan transmisi 


\section{PENDAHULUAN}

Pengembangan Pertanian dilahan kering saat ini terus dikembangkan, untuk mendorong pemanfaatan potensi lahan pertanian yang ada. Keberagaman kondisi topografi lahan eksisting, seperti lahan datar, lahan berlereng landai bahkan sampai berlereng curam, sering kali menjadi kendala dalam pengembangan usahatani di lahan kering potensial. Selain itu merubah kondisi lahan berlereng menjadi petakan lahan datar merupakan hal yang akan merubah struktur tanah dan stabilitas lahan yang ada, sehingga hal tersebut perlu dihindari dalam usahatani. Terbatasnya sumber air yang dapat dimanfaatkan juga menjadi kendala dalam pengembangan pertanian di lahan-lahan potensial berlereng tersebut. Untuk itu untuk pengembangan usahatani pada lahan berlereng, sangat memerlukan teknik-teknik irigasi yang lebih adatif agar aplikasinya lebih mudah dan sederhana.

Karakteristik wilayah dimana terdapat curah hujannya yang rendah, memerlukan pengelolaan potensi air yang ada secara efektif dan efisien, terutama di daerah potensial lahan kering. Lahan kering merupakan salah satu sumberdaya lahan yang potensial untuk dikembangkan, untuk dapat mendukung pembangunan pertanian yang lebih merata. Dengan adanya sistem irigasi yang sesuai kondisi lapangan, diharapkan nanti pengolahan atau penyiapan lahan pertanian tidak perlu menghabiskan biaya yang mahal.

Selain itu dengan ketersediaan air yang dimanfaatkan seharusnya sesuai dengan kebutuhan irigasi tanaman terutama kaitannya dengan kualitasnya. Menurut Yusuf (2014) berdasarkan hasil penelitiannya tentang mutu air untuk irigasi bahwa seyogianya dari Peraturan Pemerintah No.82 Tahun 2001 masih berlaku sebagai acuan penetapan baku mutu air saja, sedangkan baku mutu air untuk berbagai pemanfaatan misalnya irigasi dapat ditetapkan oleh pemerintah lain seperti Pemerintah/Gubernur/Bupati/ Walikota sesuai kemangannya.

Saat ini sudah banyak sistem irigasi yang ada seperti sistem irigasi sprinkler yang sudah dikembangkan, tetapi untuk lahan berlereng masih diperlukan sistem irigasi yang lain yang lebih sederhana dan dapat memanfaatkan kemiringan lahan yang ada. Dalam hal ini sistem irigasi dengan pipa perforasi yang sangat jarang digunakan, mempunyai peluang besar untuk diterapkan pada lahan berlereng di lahan kering. Sistem perforasi memerlukan tekanaan air untuk memberi irigasi ke tanaman dan sama halnya dengan sistem irigasi sprinkler. Pada sistem pipa perforasi 
hanya menggunakan pipa yang diberi lubang dan tekanan air akan mendorong air memancar keluar dari pipa secara statis, pancaran air tersebut dimanfaatkan untuk memberi irigasi pada tanaman di lahan. Untuk itu pada daerah-daerah yang berlereng ataupun berbukit, sistem ini diharapkan bisa menjadi salah satu pilihan sistem irigasi yang efisien untuk daerah tersebut.

Menurut Ardhigunawan \& Negara (2010), uji irigasi sprinkler mini type (serly) menggunakan tandon air menunjukkan hasil bahwa penambahan tinggi muka air tandon $0.5 \mathrm{~m}$ dapat meningkatkan radius pancaran sprinkler mini sekitar $66 \mathrm{~cm}$ dan peningkatan ketinggian air akan meningkatan pancaran yang terjadi pada jaringan sprinkler seri.

Menurut Negara, Saadi, \& Putra (2015) hasil uji jaringan irigasi dengan 8 buah sprinkler mini tiga nozzle di laboratorium diperoleh hasil uji dengan panjang pancaran irigasi rata-rata $2.44 \mathrm{~m}$ dengan luas areal yang dapat basahan irigasi $18.8 \mathrm{~m}^{2}$ tiap-tiap sprinkler.

Selain itu Negara \& Supriyadi (2016) menyebutkan bahwa hasil uji 8 sprinkler mini tiga nozzle pada jaringan irigasi di lahan kering Pringgabaya menunjukkan hasil diameter pancaran irigasi sprinkler rata-rata sekitar $3 \mathrm{~m}$ dengan luas basahan irigasi sekitar $26.9 \mathrm{~m}^{2}$ untuk tiap sprinkler tetapi keonfisien keseragaman (CU) yang diperoleh masih dibawah $80 \%$.

Sedangkan menurut Gultom, Agustina, \& Mursidi (2012) penelitian menguji variasi ketinggian dan diameter nozzle pada irigasi curah menunjukkan hasil keseragaman $80.51 \%$ pada variasi ketinggian $2 \mathrm{~m}$ dan diameter nozzle $3 \mathrm{~mm}$, jadi belum mampu memperoleh keseragaman diatas $85 \%$.

Berdasarkan hasil peneliti pancaran sprinkler tersebut di atas diperkirakan dapat dipakai acuan sementara untuk menilai pancaran irigasi pipa perforasi, karena sistem pipa perforasi tidak memerlukan alat pemancar khusus sehingga diharapkan dalam irigasi dapat dilakukan dengan lebih efisien, penyiapan lahan menjadi lebih mudah dan biaya untuk peralatannya tidak mahal. Untuk itu penelitian berupa eksperimen sistem irigasi perforasi dengan variasi sudut kemiringan pipa transmisi tertentu, agar pengaruhnya terhadap kinerja irigasi seperti keseragaman irigasinya (CU), panjang pancarannya (L) dan tinggi tekanan yang diperlukan dapat diketahui. Panjang pancaran irigasi sangat menentukan luas areal yang dapat diberi irigasi, sehingga hasilnya perlu diketahui dalam penelitian ini. 
Penelitian bertujuan untuk mengetahui pengaruh variasi kemiringan pipa transmisi terhadap head, keseragaman irigasi, dan panjang pancaran irigasi perforasi. Dengan uji eksperimental menggunakan variasi kemiringan lereng lahan $10^{\circ}, 20^{\circ}, 30^{\circ}$ dan $40^{\circ}$ diharapkan dapat diperoleh gambaran tentang jangkauan luas lahan yang mampu diairi oleh sistem irigasi ini. Dengan hasil penelitian ini diharapkan nanti dapat dimanfaatkan untuk perancangan sistem irigasi perforasi pada lahan dengan kelerngan salah satu dari yang telah diuji.

\section{KAJIAN PUSTAKA}

\subsection{Irigasi Pancaran}

Kinerja (performance) alat pencurah dinyatakan dalam lima parameter, yaitu debit sprinkler (sprinkler discharge), jarak pancaran (distance of throw), pola sebaran air (distribution pattern), harga pemberian air (application rate), dan ukuran rintik (droplet size) (James, 1988). Kinerja irigasi sprinkler yang optimal merupakan hasil dari perancangan dan pengelolaan sistem irigasi yang baik. Oleh karena itu kriteria teknis perancangan perlu digunakan untuk mengoptimalkan pengelolaan irigasi sprinkler berdasarkan faktor-faktor perancangan dan parameter iklim (Sheikhesmaeili, Montero, \& Laserna, 2016 dalam Tusi \& Lanya, 2016).
Menurut Ardhigunawan \& Negara (2010) pengujian sprinkler mini terhadap jarak pancaran dan kedalaman basahan irigasi menunjukkan hasil bahwa penambahan ketingian air $0.5 \mathrm{~m}$ di tandon dapat memberikan tambahan radius pancaran sekitar $66 \mathrm{~cm}$, dimana pada pengaturan tinggi air di tandon maksimum $3.5 \mathrm{~m}$ diperoleh pancaran sprinkler $488 \mathrm{~cm}$ dan pada pengaturan minimun diperoleh pancaran $342 \mathrm{~cm}$.

\subsection{Keseragaman Irigasi}

Nilai keseragaman sebaran air dinyatakan dengan suatu parameter yang disebut koefisien keseragaman (uniformity coefficient, $\mathrm{Cu}$ ). Koefisien keseragaman $\mathrm{C} \mathrm{Cu}$ dipengaruhi oleh hubungan antara tekanan, ukuran nozzle, spasing sprinkler dan kondisi angin. Koefisien keseragaman dapat dihitung dengan persamaan di bawah (Christiansen, 1942 dalam Negara et al., 2015):

$$
\begin{aligned}
& \mathrm{CU}=100 \% \cdot\left(1-\frac{\mathrm{D}}{\overline{\mathrm{y}}}\right) \ldots \\
& \mathrm{D}=\sqrt{\frac{\Sigma(\mathrm{yi}-\overline{\mathrm{y}})^{2}}{\mathrm{n}-1}} \ldots \ldots \ldots \ldots . . . . .
\end{aligned}
$$

dengan:

$\mathrm{CU}=$ koefisien keseragaman $(\%)$

$\mathrm{D}=$ deviasi standar

$\overline{\mathrm{y}}=$ harga rata-rata observasi

yi = nilai tiap-tiap observasi

$\mathrm{n} \quad=$ jumlah titik observasi 


\subsection{Kehilangan Tenaga Primer}

Kehilangan tenaga primer adalah kehilangan tenaga akibat gesekan didalam pipa. Untuk mengetahui besarnya kehilangan tenaga primer dianalisis dengan persamaan Darcy-Weiscbach sebagai berikut (Triatmodjo, 2003):

$$
\mathrm{hf}=\frac{\mathrm{f} \times \mathrm{L} \times \mathrm{V}^{2}}{\mathrm{D} \times 2 \mathrm{~g}}
$$

dengan:

hf = kehilangan tenaga $(\mathrm{m})$

$\mathrm{f} \quad=$ koefisien gesekan pipa

$\mathrm{L}=$ panjang pipa $(\mathrm{m})$

$\mathrm{D}=$ diameter pipa $(\mathrm{m})$

$\mathrm{g}=\operatorname{gravitasi}$ bumi $\left(\mathrm{m} / \mathrm{dt}^{2}\right)$

Besarnya koefisien gesekan (f) pipa didapatkan dari persamaan berikut (Triatmodjo, 2003):

1. Jika aliran pada pipa bersifat laminer $(\operatorname{Re}<2000)$ maka koefisien gesekan dapat dicari dengan persamaan berikut:

$\mathrm{f}=\frac{64}{\mathrm{Re}}$

2. Jika aliran pada pipa bersifat turbulen $(\operatorname{Re}>4000)$ maka koefisien gesekan dapat dicari menggunakan persamaan di bawah ini:

$f=\frac{0.316}{\operatorname{Re}^{0.25}}$

3. Jika aliran dalam pipa bersifat transisi $(2000<\operatorname{Re}<4000)$ maka koefisien gesekan dapat dicari menggunakan persamaan di bawah ini:

$\frac{1}{V_{\mathrm{f}}}=2 \log \frac{\mathrm{Re}{ }_{\mathrm{f}}}{2.5}$

Ketiga persamaan diatas digunakan pada pipa halus dan nilai Re didapatkan dari persamaan Reynolds di bawah ini (Triatmodjo, 2003).

$\operatorname{Re}=\frac{\mathrm{V} \mathrm{D}}{\mathrm{v}}$

dengan:

$\mathrm{f}=$ koefisien gesekan

$\mathrm{Re}=$ angka Reynolds

$\mathrm{V}=\operatorname{Kecepatan}$ aliran $(\mathrm{m} / \mathrm{dt})$

$\mathrm{D}=$ diameter pipa $(\mathrm{m})$

$v=$ viskositas kinematic $\left(\mathrm{m}^{2} / \mathrm{dt}\right)$

Besarnya kekentalan dari air digunakan nilai dari Tabel 1 berikut.

Tabel 1. Sifat-Sifat Air pada Tekanan Atmosfer

\begin{tabular}{cc}
\hline Suhu $\left({ }^{\circ} \mathrm{C}\right)$ & $\begin{array}{c}\text { Viskositas Kinemantik } \\
\left(\mathrm{m}^{2} / \mathrm{dt}\right)\end{array}$ \\
\hline 0.0 & $1.792 \times 10^{-6}$ \\
5.0 & 1.519 \\
10.0 & 1.308 \\
20.0 & 1.007 \\
30.0 & 0.804 \\
40.0 & 0.661 \\
50.0 & 0.556 \\
60.0 & 0.477 \\
70.0 & 0.415 \\
80.0 & 0.367 \\
90.0 & 0.328 \\
100.0 & $0.296 \times 10^{-6}$ \\
\hline
\end{tabular}

Sumber: Triatmodjo, 2003 


\subsection{Kehilangan Tenaga Sekunder}

Kehilangan tenaga sekunder adalah kehilangan tenaga yang diakibatkan oleh perubahan penampang, sambungan, belokan dan katub. Pada penggunaan pipa panjang biasanya kehilangan tenaga primer lebih besar dari pada tenaga sekunder, sehingga tenaga sekunder dapat diabaikan, apabila kehilangan tenaga sekunder kurang dari 5\% dari kehilangan tenaga primer maka kehilangan tenaga sekunder dapat diabaikan (Triatmodjo, 2003).

\subsubsection{Kehialangan Energi Lubang Pemasukan Pipa}

Pada lubang masuk dari kolam ke pipa, kehilangan tenaga berrgantung pada bentuk pemasukan pipa Gambar 1 ditunjukkan bentuk lubang pemasukan dan nilai koefisien $\mathrm{k}$.

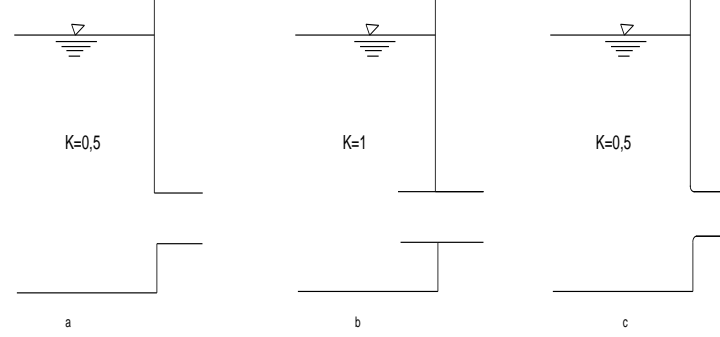

\section{Gambar 1. Bentuk bentuk lubang pemasukan pipa \\ (Sumber: Triatmodjo, 2003)}

Persamaan yang digunakan untuk menghitung kehilangan tenaga pada lubang pemasukan pipa adalah sebagai berikut (Triatmodjo, 1993):

$$
\text { he }=\mathrm{K} \frac{\mathrm{V}^{2}}{2 \mathrm{~g}}
$$

dengan:

$$
\begin{aligned}
\text { he }= & \text { kehilangan tekanan }(\mathrm{m}) \\
\mathrm{g}= & \text { gravitasi bumi }\left(\mathrm{m} / \mathrm{dt}^{2}\right) \\
\mathrm{K}= & \text { koefisien, } \\
\mathrm{V}= & \text { kecepatan aliran pada pipa } \\
& (\mathrm{m} / \mathrm{dt})
\end{aligned}
$$

\subsubsection{Kehilangan tenaga pada lubang pengeluaran}

Kehilangan tenaga akibat lubang pengeluaran (outlet) ditentukan dengan persamaan:

$$
\text { he }=\mathrm{K} \frac{\mathrm{V}^{2}}{2 \mathrm{~g}}
$$

dengan nilai $\mathrm{K}$ pada outlet $=1$ (Triatmodjo, 2003).

\subsubsection{Kehilang tenaga pada belokan Pipa}

Tenaga yang terjadi pada belokan pipa tergantung dari sudut belokan pipa. Rumus kehilangan pada belokan pipa adalah serupa rumus pada perubahan penampang adalah sebagai berikut (Triatmodjo, 2003):

$$
\text { he }=\mathrm{Kb} \frac{\mathrm{V}^{2}}{2 \mathrm{~g}}
$$

dengan:

$$
\begin{aligned}
\text { he }= & \text { kehilangan tekanan }(\mathrm{m}) \\
\mathrm{g}= & \text { gravitasi bumi }\left(\mathrm{m} / \mathrm{dt}^{2}\right) \\
\mathrm{Kb}= & \text { koefisien belokan } \\
\mathrm{V}= & \text { kecepatan aliran pada pipa } \\
& (\mathrm{m} / \mathrm{dt})
\end{aligned}
$$


Besanya koefisien (Kb) adalah koefisien kehilangan tenaga pada belokan yang dapat dilihat pada Tabel 2.

Tabel 2. Koefisien Kb Fungsi Sudut Belokan $\alpha$

\begin{tabular}{cccccc}
\hline$\alpha$ & $20^{0}$ & $40^{0}$ & $60^{0}$ & $80^{0}$ & $90^{0}$ \\
\hline $\mathrm{Kb}$ & 0.05 & 0.14 & 0.36 & 0.74 & 0.98 \\
\hline
\end{tabular}

Sumber: Triatmodjo, 2003

\subsection{Persamaan Bernoulli}

Menurut persamaan Bernoulli kehilangan tenaga terjadi karena adanya gesekan antara zat cair dengan dinding batas disebut kehilangan tenaga primer (hf) atau karena adanya perubahan penampang (he). Sehingga persamaan Bernoulli digunakan dalam perhitungan kehilangan tenaga untuk mengetahui tekanan yang terjadi pada jaringan pipa adalah sebagai berikut (Triatmodjo, 2003):

$$
\begin{aligned}
& \mathrm{Z} 1+\frac{\mathrm{P} 1}{\gamma}+\frac{\mathrm{V} 1^{2}}{2 \mathrm{~g}}=\mathrm{Z} 2+\frac{\mathrm{P} 2}{\gamma}+ \\
& \frac{\mathrm{V}^{2}}{2 \mathrm{~g}}+\Sigma \mathrm{hf}+\Sigma \mathrm{he} \\
& \text { dengan: } \\
& \mathrm{Z}=\text { elevasi pipa }(\mathrm{m}) \\
& \mathrm{P}=\text { tekanan pada pipa }\left(\mathrm{kgf} / \mathrm{m}^{2}\right) \\
& \gamma=\text { berat jenis air }\left(\mathrm{kgf} / \mathrm{m}^{3}\right) \\
& \mathrm{V}=\operatorname{kecepatan} \operatorname{aliran}(\mathrm{m} / \mathrm{dt}) \\
& \text { hf = kehilangan tenaga }(\mathrm{m}) \\
& \text { he }=\text { kehilangan tekanan }(\mathrm{m}) \\
& \mathrm{g}=\text { gravitasi bumi }\left(\mathrm{m} / \mathrm{dt}^{2}\right) \\
& \Delta \mathrm{Z}=\text { beda tinggi }(\mathrm{m})
\end{aligned}
$$

\section{METODE PENELITIAN}

\subsection{Lokasi Penelitian}

Penelitian ini dilakukan di Laboratorium Hidrolika dan Pantai Fakultas Teknik Universitas Mataram.

\subsection{Bahan Jaringan Pipa Perporasi}

Bahan yang digunakan dalam pembuatan jaringan irigasi perforasi yang diuji adalah pipa pvc $1 / 2$ inchi untuk transmisi dan jaringan pipa perforasi lateral terdiri dari 3 pipa, dengan jarak antara pipa $0.80 \mathrm{~m}$ dan jarak lubang perforasi $0.60 \mathrm{~m}$. Panjang pipa lateral yang gunakan masingmasing $4 \mathrm{~m}$, dan denah jaringan dapat dilihat Gambar 2.

\subsection{Alat}

Alat yang dimaksudkan disini adalah alat untuk membantu penelitiannya yang mencakup alat penampung berupa gelas plastic, drum penampung air 2 buah dan rangka tower air dari rangka bambu setinggi 3.3 m, seperti ditunjukkan pada Gambar 3 .

\subsection{Tahap Pengujian}

Pengujian jaringan pipa perforasi dilakukan terhadap variasi uji kemiringan pipa transmisinya adalah $10^{\circ}, 20^{\circ}, 30^{\circ}$ dan $40^{\circ}$. Variasi head (h) yang diperoleh dari variasi kemiringan pipa transmisi yang 
besarnya adalah head $130 \mathrm{~cm}$, head $185 \mathrm{~cm}$, lateral. Pengukuran dan penentuan headhead $235 \mathrm{~cm}$ dan head $285.5 \mathrm{~cm}$, dan head head yang dihasilkan dari variasi tersebut diukur dari muka air drum sampai kemiringan pipa transmisi. pada belokan pipa transmisi menuju pipa

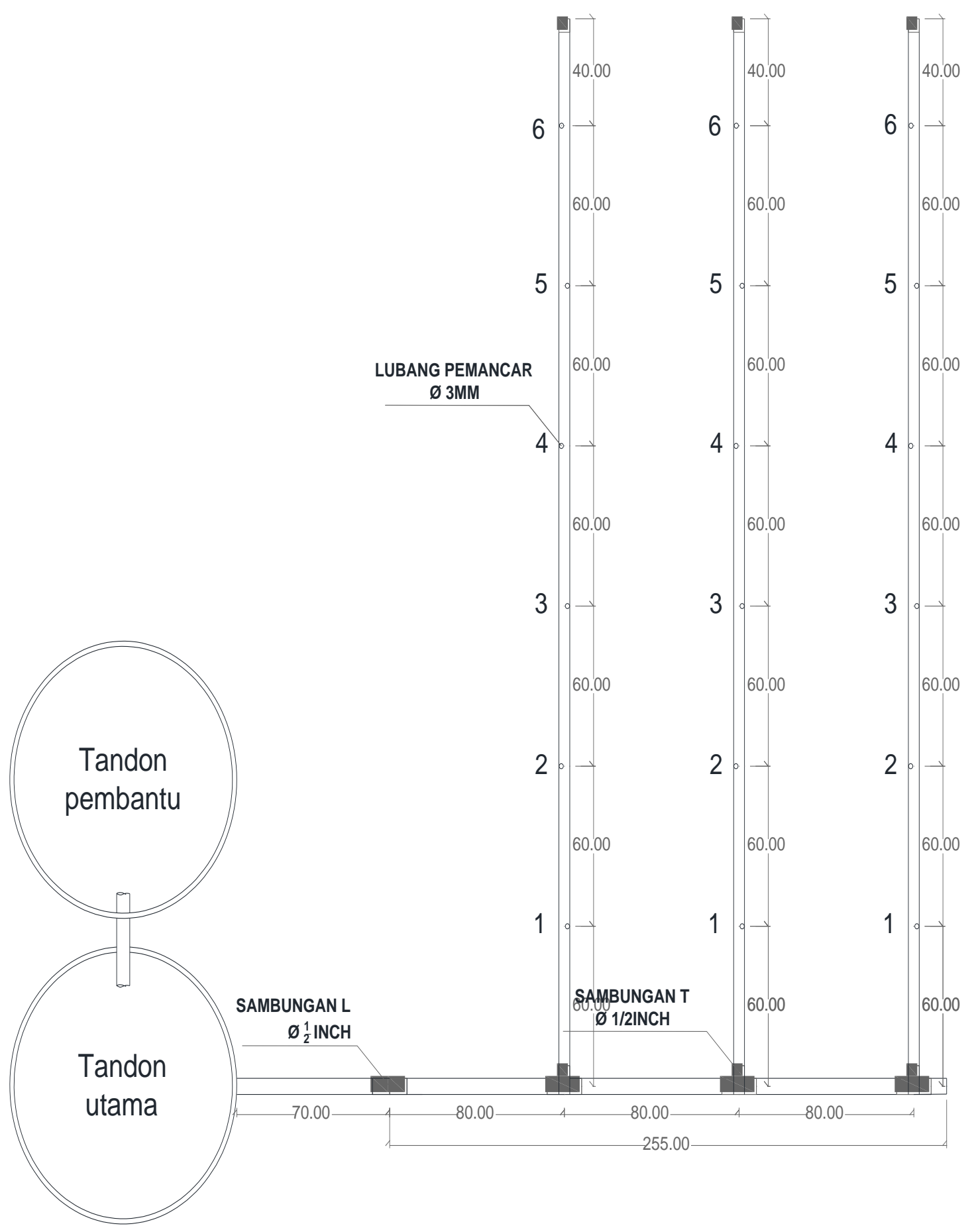

Gambar 2. Denah Jaringan Irigasi Perforasi 


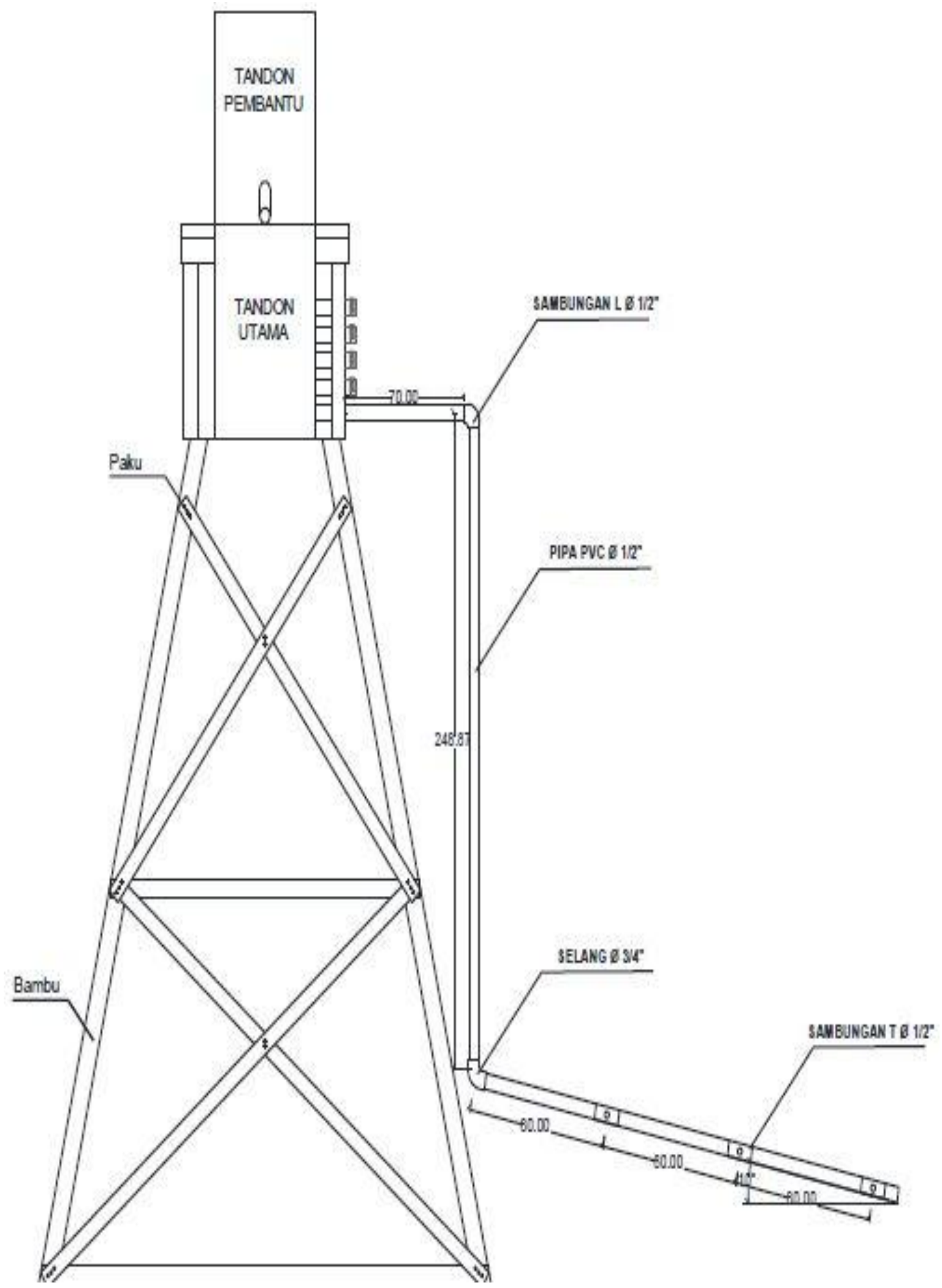

Gambar 3. Rancangan Uji Jaringan Irigasi Perforasi Tampak Samping 
Setelah peralatan siap terpasang, maka dilakukan uji awal irigasi sesuai kemiringan uji yang telah direncanakan, untuk menjamin jaringan irigasi dan pengaliran yang terjadi baik.

Langkah-langkah yang dilakukan pada pengujian adalah:

1. Penyiapan air dalam drum tower hingga penuh.

2. Penyiapan variasi kemiringan pipa transmisi.

3. Penyiapan elevasi muka air dari drum tower dan pengujian pancaran awal untuk menentukan letak titik penempatan mangkuk plastik. Aliran irigasi di running selama periode pengaliran 1 menit, 3 menit dan 5 menit, pada saat alat sudah stabil dimana pancaran air pada tiap titik pancaran sudah teratur, diperoleh $\begin{array}{llll}\text { berjarak } & 0.7 & \mathrm{~m} & \text { sehingga }\end{array}$ pemasangan mangkuk tiap-tiap jarak $0.7 \mathrm{~m}$.

4. Mengukur volume air yang tertampung pada mangkuk plastik dengan gelas ukur.Pengukuran hasil penampungan hasil uji irigasi perforasi dilakukan sebanyak 3 kali dan hasilnya diambil satu data dicatat dari hasil rataratanya.

5. Data yang dikumpulkan pada setiap pengujian mencakup, data distribusi volume tampungan mankguk plastic untuk perhitungan keseragaman irigasi (CU), data panjang pancaran irigasi perforasi (L), tata tinggi head dan variasi sudut kemiringan pipa transmisi.

6. Analisis data uji dan pembahasan. Analisisi data dilakukan terhadap data tersebut di atas, sedangkan dalam analisis akan dicari hubungan antara variasi kemiringan pipa perforasi terhadap keseragaman (CU), hubungan variasi head terhadap panjang pancaran irigasi perforasi, analisis kehilangan energi dan hubungan antara variasi kemiringan pipa perforasi terhadap Panjang pancaran irigasi perforasi.

7. Hasil analisis data ditampilkan dalam bentuk tabel dan grafik serta dibahas, sedangkan penyimpulan hasil analisis dilakukan secara deskriptif. 


\section{HASIL DAN PEMBAHASAN}

\subsection{Kehilangan Energi Pipa Perforasi}

Analisis kehilangan energi jaringan pipa perforasi dengan Persamaan 3 sampai dengan Persamaan 11, diperoleh hasil analisis berupa grafik hubungan besarnya kehilangan energi terhadap posisi pipa lateral seperti Gambar 4. Grafik menunjukkan bahwa ke tiga pipa lateral perforasi mempunyai kecenderungan kehilangan energi yang sama, dimana semakin jauh letak titik perforasi tersebut dari sumber airnya maka kehilangan energinya semakin besar.

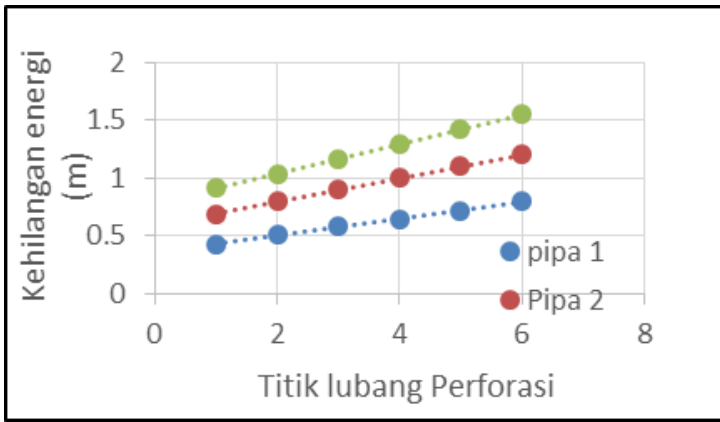

Gambar 4. Grafik Hubungan Letak Titik Pipa Perforasi Terhadap Kehilangan Energi

Dalam kasus ini, pipa 1 mempunyai kehilangan energi paling rendah karena paling dekat dengan sumber airnya , sedangkan pipa 3 mempunyai kehilangan tenaga tertinggi karena letaknya paling jauh dari sumber air. Kehilangan tenaga rata-rata dari masing-masing pipa lateral besarnya sekitar $60 \mathrm{~cm}$.

\subsection{Pengaruh Kemiringan Terhadap Head}

Hubungan pengaruh kemiringan pipa transmisi terhadap tinggi head dapat dilihat pada Gambar 5. Grafik tersebut merupakan hasil plot data hasil pengukuran terhadap kemiringan pipa transmisi yang diuji.

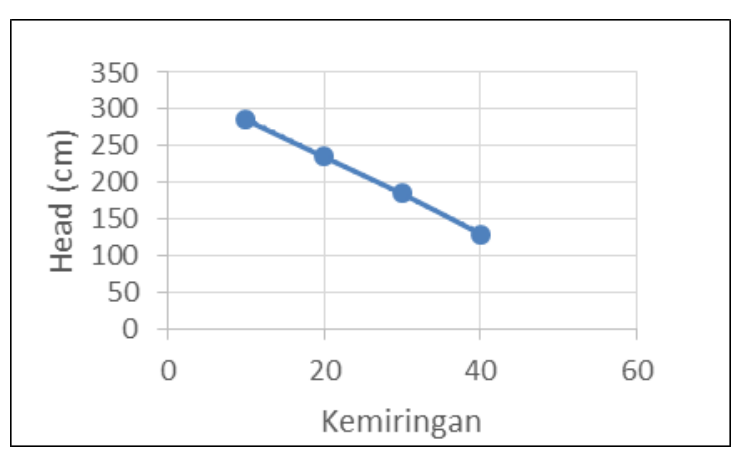

Gambar 5. Hubungan Kemiringan dengan Tinggi Head

Berdasarkan Gambar 5 diketahui bahwa besarnya kemiringan dari pipa transmisi sangat berpengaruh pada tinggi head yang dihasilkan, untuk kemiringan pipa semakin besar maka head yang dihasilkan semakin menurun. Head terbesar diperoleh pada kemiringan $10^{\circ}$ yaitu sebesar $285 \mathrm{~cm}$, sedangkan pada kemiringan $40^{\circ}$ diperoleh head $130 \mathrm{~cm}$.

\subsection{Keseragaman Irigasi (CU)}

Uji keseragaman sistem irigasi pipa perforasi digunakan persamaan 1 , dan jarak mangkuk penampung pancaran irigasi perforasi sekitar $70 \mathrm{~cm}$ seperti pada Gambar 6. 


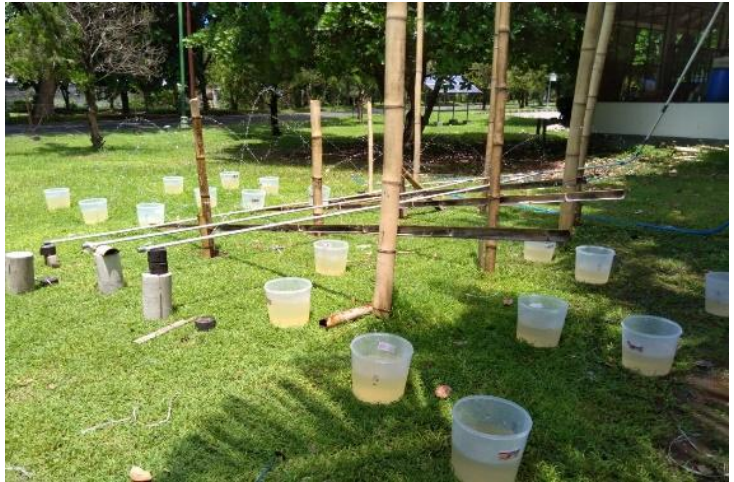

Gambar 6. Penempatan Mangkuk Penampung Uji Keseragaman

Hasil analisis uji keseragaman dibuat hubungan dalam bentuk grafik antara keseragaman dan kemiringan pipa transmisi yang ditunjukkan pada Gambar 7.

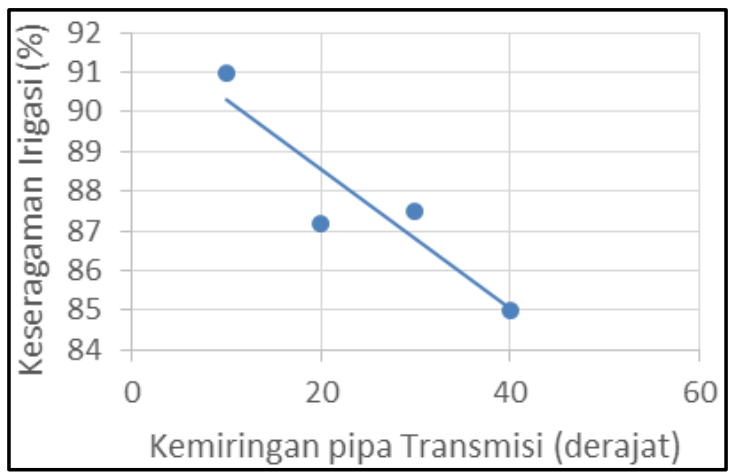

Gambar 7. Hubungan Kemiringan Pipa Transmisi dan Keseragaman Irigasi

Berdasarkan Gambar 7 diketahui bahwa keseragaman irigasi sangat dipengaruhi oleh kemiringan pipa transmisi, semakin miring pipa tansmisinya maka keseragaman aliran yang diperoleh akan semakin rendah. Nilai keseragaman minimal yang diperoleh sebesar $85 \%$ pada kemirngan $40^{\circ}$ dan nilai keseragaman maksimum sebesar 91\% diperoleh pada kemiringan $10^{\circ}$.
Keseragaman $85 \%$ dan $91 \%$ yang dihasilkan menunjukkan bahwa distribusi air irigasi perforasi yang dihasilkan $85 \%$ dan $91 \%$ seragam yang artinya masih terdapat perbedaan $15 \%$ dan $9 \%$ distribusi pancaran air irigasi yang ditampung oleh antara mangkuk yang satu dengan mangkuk yang lainnya.

Jika dibandingkan dengan hasil uji irigasi pancaran yang dilakukan oleh (Gultom et al., 2012), keseragaman irigasi perforasi hasilnya masih lebih tinggi dari sistem irigasi pancaran ini. Sehingga cara irigasi perforasi masih berpeluang digunakan untuk pemberian irigasi tanaman.

\subsection{Pancaran Pipa Perforasi}

Data hasil pengukuran pancaran pipa perforasi terhadap posisi pipa lateral, jika dibuat dalam bentuk grafik dapat dilihat pada Gambar 8. Hubungan panjang pancaran perforasi hubungannya dengan tiga posisi pipa lateral maka dapat diambil kesimpulan bahwa hasil panjang pancaran perforasi akan semakin pendek jika posisi pipa lateral semakin jauh dari sumber airnya. Dalam penelitian ini pipa lateral 1 merupakan pipa lateral yang letaknya paling jauh dalam jaringan. 


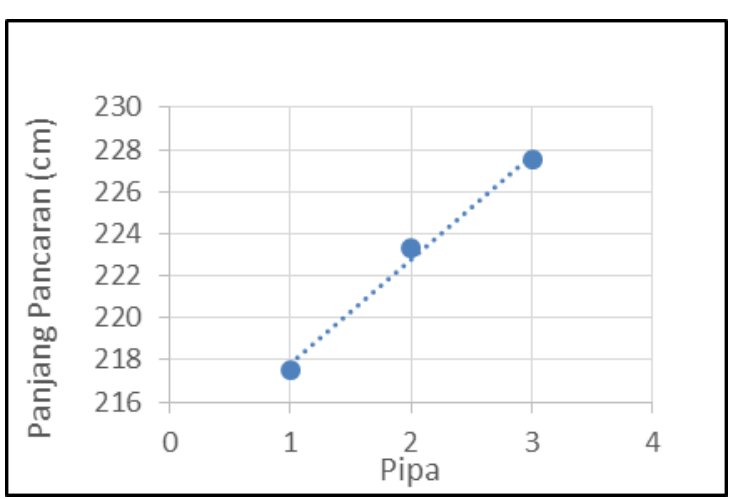

Gambar 8. Hubungan antara Panjang Pancaran Perforasi dan Posisi Pipa Lateral $1,2,3$

Memperhatikan jarak antar pipa lateral tersebut pada jaringan pipa paralel sekitar $80 \mathrm{~cm}$, dimana hasil pancaran minimal yang diperoleh sekitar $218 \mathrm{~cm}$ dan ini berarti bahwa air irigasi perforasi dapat mencakup areal sekitar $400 \mathrm{~cm}$ x $218 \mathrm{~cm} \mathrm{x}$ 2 sisi pipa lateral. Dengan penyusun lubang pipa perforasi pipa lateral secara zig-zag maka akan diperoleh jangkauan irigasi lebih merata sepanjang pipa lateral.

\subsection{Pancaran Pipa Perforasi}

Kemampuan pancaran pipa perporasi dari segi panjang pancaran (L) dan keseragaman (CU) terhadap variasi kemiringan pipa transmisi dan head, dapat dilihat pada Tabel 3.

Tabel 3. Hasil Uji pada Head

\begin{tabular}{cccc}
\hline $\begin{array}{c}\text { Kemiringan } \\
\text { derajat }\left({ }^{\circ}\right)\end{array}$ & $\begin{array}{c}\text { Head } \\
\mathrm{cm}\end{array}$ & $\begin{array}{c}\mathrm{L} \\
\mathrm{cm}\end{array}$ & $\begin{array}{c}\mathrm{CU} \\
\%\end{array}$ \\
\hline 10 & 130 & 219 & 91 \\
20 & 185 & 266 & 87.2 \\
30 & 235 & 240 & 87.5 \\
40 & 285.5 & 222 & 85 \\
\hline
\end{tabular}

Berdasarkan Tabel 3 diketahui bahwa, hasil panjang pancaran irigasi perporasi besarnya masih bervasiasi. Panjang pancaran perforasi nilainya terbesar diperoleh sebesar $266 \mathrm{~cm}$ pada kemiringan pipa transmisi $20^{\circ}$ dan diperoleh panjang pancaran sebesar $240 \mathrm{~cm}$ pada kemiringan pipa transmisi $30^{\circ}$. Panjang pancaran irigasi perforasi nilainya yang rendah diperoleh pada kemiringan pipa transmisi $10^{\circ}$ dan $40^{\circ}$, dengan panjang pancaran yang diperoleh nilainya lebih rendah dengan nilai masing-masing $219 \mathrm{~cm}$ dan $222 \mathrm{~cm}$.

Selain itu peningkatan head $55 \mathrm{~cm}$ pada kemiringan pipa transmisi dari $10^{\circ} \mathrm{ke}$ $20^{\circ}$, diperoleh pertambahan panjang pancaran sekitar $47 \mathrm{~cm}$, sedangkan pada sudut kemiringan pipa transmisi $30^{\circ} \mathrm{ke} 40^{\circ}$ diperoleh panjang pancaran nilainya menurun sebesar $18 \mathrm{~cm}$, dari besarnya 240 $\mathrm{cm}$ menjadi $222 \mathrm{~cm}$.

Bila dibandingan dengan hasil penelitian Ardhigunawan \& Negara, (2010), dimana panjang pancaran sprinkler diperoleh tambahan $0.66 \mathrm{~m}$ ketika muka air tandon dinaikan $0.50 \mathrm{~m}$. Sedangkan pada pipa perporasi dengan penambahan head $0.55 \mathrm{~m}$ dapat menghasilkan tambahan panjang pancaran irigasi $0.47 \mathrm{~m}$. Jadi terdapat kemiripan trend hasil uji akibat penambahan elevasi muka air tandon pada 
uji sprinkler, dengan penambahan tinggi head pada uji irigasi pipa perforasi pada sudut kemiringan pipa transmisi $10^{\circ}-30^{\circ}$ saja.

Jika dilihat berdasarkan panjang pancaran yang diperoleh sistem jaringan pipa perforasi terhadap sprinkler mini tiga nozzle yang diuji Negara et al. (2015) dan Negara \& Supriyadi (2016), maka walaupun hasil pancaran yang diperoleh sprinkler mini masih mendekati hasil uji pancaran sistem perforasi tetapi keseragamannya belum mampu mencapai yang dihasilkan pipa perforasi dimana CU di atas $85 \%$. Oleh karena itu dengan mengetahui potensi yang ditunjukkan oleh sistem irigasi pipa perforasi, maka sistem irigasi pipa perforasi lebih mungkin diterapkan untuk pemberian irigasi pada tanaman tertentu dari pada sistem sprinkler tiga nozzle. Oleh karena itu maka pada sudut tersebut, jaringan pipa perforasi mempunyai potensi dimanfaatkan untuk irigasi, sedangkan pada sudut kemiringan pipa transmisi $30^{\circ}$ dan $40^{\circ}$ tidak disarankan untuk diterapkan.

\section{SIMPULAN}

Kesimpulan dapat diambil dari analisis yang dilakukan adalah sebagai berikut:
1. Semakin besar kemiringan pipa transmisi maka head yang dihasilkan semakin tinggi.

2. Keseragaman irigasi yang dihasilkan pipa perforasi akan semakin kecil jika miring pipa transmisi semakin besar. Keseragaman minimum yang dihasilkan sebesar $85 \%$ sedangan yang tertinggi $91 \%$.

3. Pancaran irigasi perforasi nilainya yang besar diperoleh pada kemiringan transmisi $20^{\circ}$ dan $30^{\circ}$ yaitu $266 \mathrm{~cm}$ dan $240 \mathrm{~cm}$ sedangkan pada kemiringan $10^{\circ}$ dan $40^{\circ}$ cenderung lebih rendah.

\section{DAFTAR PUSTAKA}

Ardhigunawan, \& Negara, I. D. G. J. (2010). Analisis Kinerja Sprinkler Mini terhadap Jarak Pancaran dan Estimasi Kedalaman Capaian Irigasi. Spektrum Sipil Jurnal Keilmuan Dan Aplikasi Teknik Sipil, 1(3), 163-238.

Gultom, M. A., Agustina, H., \& Mursidi, R. (2012). Variasi Diameter Nosel dan Ketinggian Penyiraman Menggunakan irigasi Curah Terhadap Pemadatan Tanah. Jurnal Teknik Pertanian Sriwijaya, 1(2), 119-126.

James, L. G. (1988). Principles of Farm Irrigation System Design. New York: John Willey and Sons.

Negara, I. D. G. J., Saadi, Y., \& Putra, I. B. G. (2015). Karakteristik Kinerja sprinkler Mini pada Lahan Kering Pringgabaya Utara Kabupaten 
Lombok Timur. Spektrum Sipil Jurnal Keilmuan Dan Aplikasi Teknik Sipil, 2(1), 28-37.

Negara, I. D. G. J., \& Supriyadi, A. (2016). Analisis Rancang Bangun Sistem Irigasi Hemat Air Terpadu Berbasis Jaringan Irigasi Air Tanah (JIAT) pada Lahan Kering Tanah Bergaradasi Halus DI Pringgabaya Kabupaten Lombok Timur. Spektrum Sipil Jurnal Keilmuan Dan Aplikasi Teknik Sipil, 3(1), 49-59.

Sheikhesmaeili, O., Montero, J., \& Laserna, S. (2016). Analysis of water application with semi-portable big size sprinkler irrigation systems in semi-arid areas. Agricultural Water Management, 163, 275-284. https://doi.org/10.1016/j.agwat.2015. 10.004

Triatmodjo, B. (1993). Hidrolika II. Yogyakarta: Beta Offset.

Triatmodjo, B. (2003). Hidrolika II, Edisi II. Yogyakarta: Beta Offset.

Tusi, A., \& Lanya, B. (2016). Rancangan Irigasi Sprinkler Portable Tanaman Pakchoy. Lampung: Universitas Lampung.

Yusuf, I. A. (2014). Kajian Kriteria Mutu Air Irigasi. Jurnal Irigasi, 9(1), 1. https://doi.org/10.31028/ji.v9.i1.1-15 